3. Varlotto JM, Recht A, Flickinger JC, MedfordDavis LN, Dyer AM, DeCamp MM. Varying recurrence rates and risk factors associated with different definitions of local recurrence in patients with surgically resected, stage I nonsmall cell lung cancer. Cancer. 2010;116:2390-400.

4. Fibla JJ, Cassivi SD, Brunelli A, Decker PA, Allen MS, Darling GE, et al. Re-evaluation of the prognostic value of visceral pleura invasion in stage IB non-small cell lung cancer using the prospective multicenter ACOSOG Z0030 trial data set. Lung Cancer. 2012;78:259-62.

http://dx.doi.org/10.1016/ j.jtcvs.2013.04.048

\section{PROSTHETIC AORTIC VALVE EVALUATION: SHOULD THE ASSESSMENT OF HEMODYNAMIC PERFORMANCE DURING EXERCISE COMPLETE THE ANALYSIS? \\ To the Editor:}

In a recent publication, Suri and colleagues ${ }^{1}$ evaluated the hemodynamic performance of the latest generation of biologic aortic valve prostheses. The results evidenced small but consistent early postoperative hemodynamic differences among current third-generation bioprostheses (Edwards Magna, Sorin Mitroflow, and St Jude Epic). We read the article with interest and were also impressed by Dr David's comment in the meeting discussion. We congratulate Suri and colleagues $^{1}$ on this study; however, we would like to add some comments.

First, Suri and colleagues ${ }^{1}$ likely included in their study any type of aortic valve disease, which could be misleading for comparative results. Aortic stenosis, aortic incompetence, and their combination have differences in physiology, histology, and anatomy, leading to different behaviors after the valve replacement.

Second, patients were assessed for hemodynamic performance before hospital discharge. This is contrary to previous studies, which indicate that in vivo values should be taken at 1-year follow-up because gradients may change during the first postoperative year, with significant impact on either the hemodynamic results or the exercise capacity. ${ }^{2}$

Third, any realistic assessment of hemodynamic behavior of a prosthesis should include evaluation during exercise. Results obtained under stress are by far more suitable to evaluate the performance of a valve type than hemodynamic data obtained at rest, and they also reflect more closely the situation in daily life. In this regard, Gerosa and colleagues $^{3}$ used the Sheffield pulse duplicator to demonstrate in vitro that different prostheses perform differently in different hemodynamic circumstances. In vivo evaluations are even more difficult. Stressinduced echocardiographic assessment could be hindered by several confounding factors: heart rate, cardiac output, left ventricle diastolic pattern, hypertension, reduced systemic arterial compliance, and so on.

In a recent study, we evaluated by echocardiography the hemodynamic performance at rest and during exercise of 2 different aortic prostheses of similar size implanted in patients who underwent surgery for pure aortic stenosis. ${ }^{4}$ Although the study compared a mechanical valve with a porcine bioprosthesis, our results validated the technical procedures as model for evaluations under stress.

As we were aware that the sole measurement of gradients does not entirely represent the complex function of a valve during physical exercise, we also analyzed the stress-induced abnormalities of the cardiac cycle 1 year after aortic valve replacement. As is widely known, the total cardiac cycle duration is algebraically dependent on the heart rate $(60,000 \mathrm{~ms} /$ heart rate $)$, which is the major determinant affecting diastolic and systolic duration. Systolic time has a negative linear correlation with heart rate. Diastolic time is longer at low heart rates and decreases more markedly than systolic time during exercise. Transprosthetic gradient is a function of both diastolic duration and systolic/diastolic ratio, which depends on a number of cofactors but could also be attributed to the flexibility of the stent and the geometric design of the bioprostheses. These factors interfere with the delicate physiologic mechanism of active annulus motion and aortic root expansion at each phase of the cardiac cycle, especially during exercise. This is more valid for mechanical valves and for 19- to 23-mm bioprostheses. A meaningful evaluation of a bioprosthesis should therefore further consider the stent flexibility during exercise and the effective tolerability of its distortion when upsized.

Vito Mannacio, MD

Vincenzo De Amicis, MD

Carlo Vosa, MD

Department of Cardiac Surgery

University of Naples Federico II Naples, Italy

\section{References}

1. Suri RM, Michelena HI, Burkhart HM, Greason KL, Daly RC, Dearani JA, et al. A prospective, randomized comparison of 3 contemporary bioprosthetic aortic valves: should hemodynamic performance influence device selection? J Thorac Cardiovasc Surg. 2012;144. 1387-95, 1398; discussion 1395-7.

2. Pibarot P, Dumesnil JG. Hemodynamic and clinica impact of prosthesis-patient mismatch in the aortic valve position and its prevention. J Am Coll Cardiol. 2000;36:1131-41.

3. Gerosa G, Tarzia V, Rizzoli G, Bottio T. Small aortic annulus: the hydrodynamic performances of 5 commercially available tissue valves. $J$ Thorac Cardiovasc Surg. 2006;131:1058-64.

4. Mannacio V, Di Tommaso L, De Amicis V, Stassano P, Vosa C. Coronary perfusion: Impact of flow dynamics and geometric design of two different aortic prostheses of similar size. J Thorac Cardiovasc Surg. 2012;143:1030-5.

http://dx.doi.org/10.1016/ j.jtcvs.2013.02.085

\section{LIMITATIONS IN THE USE OF LEFT CAROTID ARTERY TURNDOWN FOR INTERRUPTED AORTIC ARCH REPAIR}

To the Editor:

Todman and associates ${ }^{1}$ recently described favorable outcomes after 